\title{
Use of the FINDRISC Questionnaire in the Uzbek Population as a First Stage of Screening for Type 2 Diabetes Mellitus
}

\author{
Anna V. Alieva, $\mathrm{PhD}^{1}$; Saydiganikhodja I. Ismailov, $\mathrm{PhD}, \mathrm{ScD}^{2 *}$; \\ Gulnara N. Rakhimova, $\mathrm{PhD}, \mathrm{ScD}^{3}$ \\ ${ }^{1}$ Republican Specialized Scientific-Practical Medical Centre of Endocrinology \\ named after Academician Ya. Kh. Turakulov \\ ${ }^{2}$ Tashkent Pediatric Medical Institute \\ ${ }^{3}$ Tashkent Institute of Postgraduate Medical Education \\ Tashkent, Uzbekistan
}

\begin{abstract}
Background: Active diagnosis of rapidly growing type 2 diabetes (T2D) is very important. Whether the FINDRISC questionnaire can be used as a first-stage screening tool in the Uzbek population is unclear, as anthropometric parameters and the impact of each risk factor may differ in different populations.

Materials and Results: In 2015-2016, regardless of nationality 2521 people (711 men and 1464 women) living in urban and rural areas of Uzbekistan were examined. The study included filling out a FINDRISC questionnaire with an assessment of the risk for T2D. All subjects underwent OGTT and HbA1c testing. The average score on the FINDRISC questionnaire among people with newly diagnosed diabetes was $12.8 \pm 0.4(P<0.001)$, for IGT $-11.4 \pm 0.4(P<0.001)$, for IFG $-11.0 \pm 0.8(P<0.001)$ compared with individuals without carbohydrate metabolism disorders ( $8.0 \pm 0.09)$. Among people with diabetes diagnosed during the screening, only $33.9 \%$ had a high $(30 \%)$ and very high (3.9\%) risk of T2D, while $27.6 \%$ had a moderate risk, $30 \%$ - an increased risk, and $8.7 \%$ - a low risk of T2D. For the FINDRISC score, the sensitivity with a threshold value of 9 points was $87.9 \%$ and specificity was $45.3 \%$; with a value of 12 points, sensitivity was $71.6 \%$ and specificity was $54.8 \%$.

Conclusion: These results were the basis for a multivariate analysis of the risk for T2D among people of Uzbek nationality, and for the development of our own risk assessment program. (International Journal of Biomedicine. 2020;10(1):29-35.)

Key Words: type 2 diabetes $\bullet$ screening $\bullet$ ethnicity $\bullet$ risk assessment

\section{Abbreviations}

ADA, American Diabetes Association; AH, arterial hypertension; BMI, body mass index; CMD, carbohydrate metabolism disorders; CDA, Canadian Diabetes Association; CVD, cardiovascular disease; DM, diabetes mellitus; HC, hip circumference; IFG, impaired fasting glucose; IGT, impaired glucose tolerance; OGTT, oral glucose tolerance test; PhA, physical activity; T2D, type 2 diabetes; WC, waist circumference; WHR, waist-to-hip ratio

\section{Introduction}

Given the dangerously rapid growth of type 2 diabetes (T2D) prevalence worldwide, ${ }^{(1)}$ active diagnosis is very important, since it has been shown that patients at the stage

*Corresponding author: Prof. Saydiganikhodja I. Ismailov, Head of the Department of Endocrinology with Pediatric Endocrinology, Tashkent Pediatric Medical Institute.E-mail: ismailov.said@list.ru

of prediabetes already have diabetes-specific complications (IFG and IGT). ${ }^{(2-4)}$ The diabetes screening strategy proposed by WHO in 2003 has a two-step approach. ${ }^{(5)}$ At the first stage, the risk groups for developing diabetes are identified:

1. All persons aged 45 or older

2. Persons younger than 45 having at least one of the following factors:

- Obesity

- Family history of diabetes
\end{abstract}


- Ethnicity

- History of gestational diabetes

- Birth of a child weighing more than $4.5 \mathrm{~kg}$

- Arterial hypertension

- Hyperlipidemia

- Previously diagnosed IFG or IGT

At the second stage of screening, OGTT is performed in these risk groups. In cases of normal results of OGTT, diabetes prevention strategies are introduced in risk groups, and regular repeated screening for diabetes is carried out at least every 3 years. ${ }^{(5)}$

The diabetes screening strategy proposed by the International Federation of Diabetes (2017) differs in its list of risk factors: ${ }^{(3,6)}$ age over 40 ; obesity, increased WC; family history of diabetes; and arterial hypertension.

Local questionnaires (for example, FINDRISC) ${ }^{(7,8)}$ are recommended to identify risk groups; if there are no such a questionnaires, testing for fasting glycemia is recommended. ${ }^{(3)}$

$\mathrm{ADA}^{(9)}$ considers all people age 45 or older to be at risk for diabetes, and persons of any age with obesity plus:

- Family history of diabetes (first-degree relatives)

- Racial and ethnic groups at increased risk for diabetes

- History of cerebro-vascular disease (CVD)

- History of gestational diabetes

- Arterial hypertension $\mathrm{mmol} / \mathrm{L}$ )

- Dyslipidemia (HDL $<0.9 \mathrm{mmol} / \mathrm{L}$ and / or TG $>2.82$

- Women with polycystic ovary syndrome (PCOS);

- Insulin resistance (severe obesity, acantosis nigricans)

- Previously diagnosed IFG or IGT

In risk groups, it is recommended to perform OGTT and/or HbA1c testing.

The strategy proposed by the $\mathrm{CDA}^{(10)}$ differs from the ADA strategy in that it has an even more extended list of risk factors, and the threshold age for the beginning of mandatory testing is 40 years.

Risk groups for diabetes, according to $\mathrm{CDA}^{(10)}$ are:

1. All persons aged 40 or older

2. Persons of any age with obesity plus:

- Family history of diabetes (first-degree relatives)

- Racial and ethnic groups at increased risk for diabetes

- Micro and macrovascular complications

- History of gestational diabetes

- History of fetal macrosomia

- Arterial hypertension

- Dyslipidemia (HDL $<0.9 \mathrm{mmol} / \mathrm{L}$ and / or TG $>2.82$ $\mathrm{mmol} / \mathrm{L}$ )

- Women with PCOS

- Insulin resistance (severe obesity, acantosis nigricans), obstructive sleep apnea, mental disorders, HIV infection, taking glucocorticoids, atypical antipsychotics, or antiretroviral therapy

- Previously diagnosed IFG or IGT

Australian Diabetes Risk Questionnaire ${ }^{(11)}$ includes:

- Age 35 or older

- Gender (male)

- Racial and ethnic groups at increased risk for diabetes

- Family history of diabetes (first-degree relatives)
- History of hyperglycemia, history of gestational diabetes

- Arterial hypertension

- Smoking

- Insufficient vegetables and fruits consumption

- Low physical activity

- Abdominal obesity (own standards of WC for each race) Chinese authors ${ }^{(12)}$ consider the following as risk factors for T2D:

- Age

- Gender (male)

- BMI (24 and $\left.28 \mathrm{~kg} / \mathrm{m}^{2}\right)$;

- Family history of diabetes

- Level of education

- Arterial hypertension

- Heart rate at rest (70-80-90 per min)

- Fasting glycemia $(5.6-6.1-6.9 \mathrm{mmol} / \mathrm{L})$

- $\mathrm{TG} \geq 1.7 \mathrm{mmol} / \mathrm{L}$

In Japan, ${ }^{(13,14)} 2$ strategies for determining the risk of T2D are proposed. The first takes into account age, gender, BMI, WC, arterial hypertension, and smoking. The second one includes age (40 years or older), gender (male), family history of diabetes (first-degree relatives), smoking, low PhA, BMI $>23 \mathrm{~kg} / \mathrm{m}^{2}$, and arterial hypertension.

In Peru, ${ }^{(15)}$ the Ministry of Health recommends screening by testing for fasting glycemia in people aged 40 to 70 who have risk factors. However, fasting glucose testing is not available in rural settings. The risk questionnaire includes age 55 or older, family history of diabetes, and WC above $90 \mathrm{~cm}$.

The Finnish Diabetes Risk Score (FINDRISC) is one of the most frequently used instruments for assessing the risk of DM. ${ }^{(7)}$ The main points of the questionnaire include age, BMI, WC (separately for men and women), PhA, the consumption of vegetables, fruits and berries, regular use of antihypertensive drugs, a history of hyperglycemia and a family history of diabetes. The threshold for $\mathrm{WC}$ in this questionnaire is $94 \mathrm{~cm}$ for men and $80 \mathrm{~cm}$ for women; the threshold for BMI is $25 \mathrm{~kg} / \mathrm{m}^{2}$. FINDRISC assesses whether an individual has undiagnosed T2D or dysglycaemia or the probability of developing T2DM during the following 10 years. The applicability of the FINDRISC questionnaire has been evaluated in many countries. ${ }^{(16-19)}$

The recommendations on diabetes, prediabetes and cardiovascular diseases by EASD/ESC ${ }^{(19)}$ indicate the need to develop risk assessment scales for T2D and cardiovascular diseases for each specific population.

The scales and questionnaires described above are nonspecific for the Uzbek population. At the same time, there are no data on the standards of WC, WHR and BMI for those of Uzbek nationality. In this regard, conducting epidemiological screening studies to identify diabetes and prediabetes, with the study of anthropometric indicators, is very important.

\section{Materials and Methods}

\section{General characteristics of the examined persons}

In 2015-2016, regardless of nationality 2521 people (711 men and 1464 women) living in urban and rural areas of the Tashkent, Kashkadarya and Khorezm regions were examined. The target group of the study was the adult population aged 35 
or older with stratification by gender in each age group: from 35 to 44 , from 45 to 64 and over 65 , without known CMD. The average age of those examined was $48.1 \pm 11.6$ years; $68 \%$ of the examined were women.

\section{Epidemiological method}

The sample was formed by the method of random numbers, and the design of sample formation was weighed cluster. Examination was done by the same group of endocrinologists in all areas in order to eliminate errors in data collection and filling out questionnaires. A group of researchers was pre-trained and instructed on the rules of data collection, anthropometric measurements, and blood sampling for biochemical analysis.

The study included filling out a questionnaire with an assessment of the risk for T2D. The basis of the questionnaire was the WHO recommendations for screening for T2D, as well as the FINDRISC questionnaire ${ }^{(7)}$ for identifying the risk of developing T2D over the next 10 years.

\section{Anthropometry}

Previously, we proposed reference values for WC, HC, WHR and BMI for men and women of the Uzbek population. ${ }^{(20,21)}$

\section{General clinical research}

Blood pressure was measured using Korotkov's method on two hands twice. Assessment of PhA was carried out on the basis of a survey of subjects, taking into account the duration, intensity and frequency of PhA. PhA was assessed as high if a person had moderate-intensity physical exercises (walking at a moderate pace, aerobic exercise) lasting more than 300 minutes a week; high-intensity exercises (running, training on simulators, anaerobic exercises) lasting more than 150 minutes a week, or when combining medium and highintensity exercises for more than 150 minutes a week. PhA was regarded as moderate when performing physical exercises of medium intensity for 150-300 minutes per week or high intensity from 60 to 150 minutes per week. Low PhA was recorded if $\mathrm{PhA}$ of average intensity was less than 150 minutes per week or of high intensity less than an hour per week. ${ }^{(22)}$

\section{Biochemical tests}

All subjects underwent OGTT; glucose in the capillary blood plasma was measured using an iXell glucometer (Poland) with test strips calibrated in accordance with the reference values for venous blood plasma. The level of glycated hemoglobin was determined by a direct photometric immunochemical method using monoclonal antibodies to HbA1c (Human, HbA1c liquidirect, Germany) by means of a Human biochemical analyzer in the laboratory of the Republican Specialized Scientific-Practical Medical Center of Endocrinology named after Academician Ya. Kh. Turakulov. This method for HbAlc testing is standardized in accordance with the requirements of NGSP/DCCT and IFCC.

Prediabetes and diabetes were diagnosed according to the international recommendations. ${ }^{(23)}$ All persons with identified CMD were referred to an endocrinologist at the place of residence for registration and further monitoring.

Statistical analysis was performed using the Microsoft Office Excel-2016 software package. Baseline characteristics were summarized as frequencies and percentages for categorical variables and as mean \pm standard deviation (SD) for continuous variables. For data with normal distribution, inter-group comparisons were performed using Student's t-test. A probability value of $P<0.05$ was considered statistically significant.

\section{Results}

A total of 2521 people aged 35 or older living in urban and rural areas of the Tashkent, Kashkadarya and Khorezm regions were examined. T2D was diagnosed in $7.9 \%$ of the examined individuals, and in $74 \%$ of them the disease was diagnosed during the screening. Prevalence of T2D was $8.7 \%$ among men aged 35 years or older, and $7.5 \%$ among women. IFG was diagnosed in $4.4 \%$ of the examined individuals (in $2.6 \%$ of men and $5.3 \%$ of women); IGT was diagnosed in $1.4 \%$ of the examined individuals (in $0.5 \%$ of men and $1.8 \%$ of women). The average age of men and women with identified CMD was $53.3 \pm 1.27$, and for newly diagnosed T2D it was $55.7 \pm 1.07$; for IFG it was $58.5 \pm 4.63$ (men) and $54.1 \pm 2.15$ (women); for IGT it was 53.8 \pm 2.1 (men) and 55.6 \pm 1.41 (women); the average age of people without CMD was $48.3 \pm 0.44$ for men and $46.4 \pm 0.29$ for women.

All persons with newly diagnosed DM and prediabetes were referred to an endocrinologist at the place of residence for treatment and monitoring.

The overwhelming majority of people with newly diagnosed CMD admitted that they do not spend enough time on PhA: $59 \%$ of women and $70 \%$ of men with newly diagnosed $\mathrm{DM}$ rated their $\mathrm{PhA}$ as moderate, and $34 \%$ and $23 \%$, respectively, rated it as low. Patients with IFG $(66 \%$ of women and $52 \%$ of men) rated their PhA as moderate, and $25 \%$ and $38 \%$, respectively, as low. As for patients with IGT, 74\% of women and $50 \%$ of men rated their $\mathrm{PhA}$ as moderate, $19 \%$ of women as low. Since IFG was detected in only 4 men, it is premature to draw conclusions on the analysis of IFG in men.

A family history of diabetes was found in $40 \%$ of people with newly diagnosed diabetes, $36 \%$ of people with IGT and $26 \%$ of people with IFG. A family history of obesity was found in $39 \%$ of people with newly diagnosed diabetes, $34 \%$ of people with IGT, and $51 \%$ of people with IFG. An extremely high percentage of families had a history of cardiovascular diseases, in particular arterial hypertension, which are significant risk factors for T2D (Table 1).

Table 1.

Family history of individuals with identified CMD

\begin{tabular}{|l|c|c|c|c|c|c|c|c|}
\hline \multirow{2}{*}{ Family history } & \multicolumn{2}{|c|}{$\begin{array}{c}\text { Individuals } \\
\text { with newly } \\
\text { diagnosed } \\
\text { diabetes }\end{array}$} & \multicolumn{2}{|c|}{$\begin{array}{l}\text { Individuals } \\
\text { with IGT }\end{array}$} & \multicolumn{2}{|c|}{$\begin{array}{l}\text { Individuals } \\
\text { with IFG }\end{array}$} & \multicolumn{2}{|c|}{$\begin{array}{c}\text { Individuals } \\
\text { without } \\
\text { CMD }\end{array}$} \\
\cline { 2 - 10 } & men & women & men & women & men & women & men & women \\
\hline $\mathrm{n}$ & 43 & 104 & 21 & 91 & 4 & 31 & 711 & 1464 \\
\hline Obesity, \% & 35 & 41 & 29 & 35 & 25 & 55 & 26 & 39 \\
\hline $\begin{array}{l}\text { Arterial } \\
\text { hypertension, \% }\end{array}$ & 53 & 60 & 52 & 62 & 25 & 65 & 44 & 56 \\
\hline $\begin{array}{l}\text { Ischemic heart } \\
\text { disease, \% }\end{array}$ & 28 & 38 & 24 & 41 & - & 45 & 23 & 37 \\
\hline Diabetes, \% & 37 & 41 & 62 & 30 & 25 & 26 & 15 & 25 \\
\hline
\end{tabular}


We analyzed the prevalence of overweight and obesity among the subjects. In general, in the entire population of the examined, only $28.7 \%$ of people had normal weight (BMI of $\left.18-25 \mathrm{~kg} / \mathrm{m}^{2}\right) ; 70.1 \%$ were overweight or obese. Even among individuals without identified CMD, only $31 \%$ had normal weight.

Figure 1 shows the average BMI of individuals with impaired carbohydrate metabolism compared with individuals without identified carbohydrate disorders. As can be seen from the figure, the average BMI among individuals with newly diagnosed T2D was $33.0 \pm 0.7 \mathrm{~kg} / \mathrm{m}^{2}$ for women and $30.1 \pm 0.8$ $\mathrm{kg} / \mathrm{m}^{2}$ for men. The average BMI among individuals with IGT was $31.6 \pm 0.7 \mathrm{~kg} / \mathrm{m}^{2}$ for women and $30.2 \pm 1.2 \mathrm{~kg} / \mathrm{m}^{2}$ for men. The average BMI among individuals with IFG was $32.1 \pm 1.3$ $\mathrm{kg} / \mathrm{m}^{2}$ for women and $28.8 \pm 2.8 \mathrm{~kg} / \mathrm{m}^{2}$ for men. Among people without CMD, the average BMI was $27.3 \pm 0.18 \mathrm{~kg} / \mathrm{m}^{2}$ for men and $28.4 \pm 0.15 \mathrm{~kg} / \mathrm{m}^{2}$ for women.

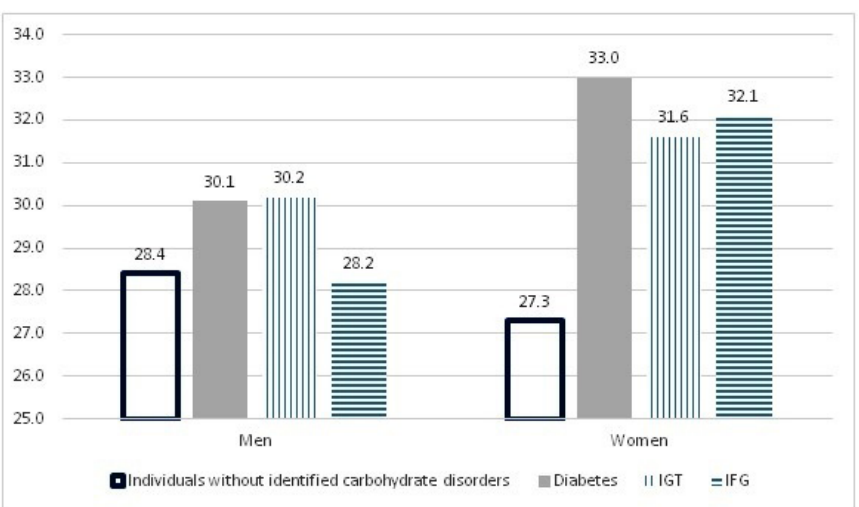

Fig.1. The average BMI $\left(\mathrm{kg} / \mathrm{m}^{2}\right)$ in individuals with impaired carbohydrate metabolism compared with individuals without identified carbohydrate disorders.

WC is one of the key indicators in diagnosing obesity and determining the risk of diabetes, according to many questionnaires. Among the individuals we examined, WC exceeded the WHO recommended values for a healthy population, even in the absence of CMD (Table 2).

\section{Table 2.}

WC and WHR in individuals without CMD and in patients with diabetes and prediabetes

\begin{tabular}{|l|c|c|c|c|c|}
\hline \multicolumn{2}{|c|}{} & $\begin{array}{c}\text { Individuals } \\
\text { without } \\
\text { CMD }\end{array}$ & Diabetes & IGT & IFG \\
\hline \multirow{2}{*}{$\begin{array}{l}\text { WC, } \\
\mathrm{cm}\end{array}$} & Men & $96.3 \pm 0.48$ & $106.9 \pm 2.1 * *$ & $103.7 \pm 2.8 *$ & $103.5 \pm 5.2$ \\
\cline { 2 - 7 } & Women & $88.7 \pm 0.37$ & $101.0 \pm 1.38 * *$ & $95.6 \pm 1.48 * *$ & $96.3 \pm 2.7 * *$ \\
\hline \multirow{2}{*}{ WHR } & Men & $0.95 \pm 0.003$ & $1.0 \pm 0.009 * *$ & $0.98 \pm 0.016$ & $0.94 \pm 0.016$ \\
\cline { 2 - 6 } & Women & $0.84 \pm 0.002$ & $0.89 \pm 0.007 * *$ & $0.87 \pm 0.007 * *$ & $0.85 \pm 0.015$ \\
\hline
\end{tabular}

$*-P<0.05$ and $* *-P<0.001$ - compared with individuals without $C M D$

Despite the high percentage of obesity among people without impaired carbohydrate metabolism, the overall average score for the FINDRISC questionnaire in these individuals was significantly lower than in groups in which diabetes, IGT, and IFG were detected (Table 3). Thus, the average score on the FINDRISC questionnaire among people with newly diagnosed diabetes was $12.8 \pm 0.4(P<0.001)$, for IGT $-11.4 \pm 0.4(P<0.001)$, for IFG $-11.0 \pm 0.8(P<0.001)$, and for people without $\mathrm{CMD}-8.0 \pm 0.09$.

Table 3.

Biochemical and anthropometric risk factors depending on the type of CMD

\begin{tabular}{|c|c|c|c|c|}
\hline & $\mathrm{T} 2 \mathrm{D}$ & IGT & IFG & $\begin{array}{l}\text { Healthy } \\
\text { subjects }\end{array}$ \\
\hline Age & $55.0 \pm 0.8^{\prime \prime}$ & $55.3 \pm 1.2^{\prime \prime}$ & $58.5 \pm 4.6^{*}$ & $47.0 \pm 0.24$ \\
\hline $\begin{array}{l}\text { Fasting glucose, } \\
\mathrm{mmol} / \mathrm{L}\end{array}$ & $9.6 \pm 0.3^{\prime \prime}$ & $5.5 \pm 0.1^{\prime \prime}$ & $6.3 \pm 0.04 "$ & $4.8 \pm 0.014$ \\
\hline OGTT, mmol/L & $13.7 \pm 0.5^{\prime \prime}$ & $9.6 \pm 0.1^{\prime \prime}$ & $6.8 \pm 0.31 "$ & $5.6 \pm 0.02$ \\
\hline HbAlc, $\%$ & $9.4 \pm 0.24 "$ & $6.2 \pm 0.1^{\prime \prime}$ & $5.7 \pm 0.2^{\prime \prime}$ & $4.9 \pm 0.015$ \\
\hline Body mass, kg & $85.2 \pm 1.5^{\prime \prime}$ & $80.1 \pm 1.6^{\wedge}$ & $83.7 \pm 3.4 *$ & $75.2 \pm 0.3$ \\
\hline BMI, kg/m² & $32.2 \pm 0.5^{\prime \prime}$ & $31.3 \pm 0.6^{\prime \prime}$ & $31.7 \pm 1.2^{\wedge}$ & $28.0 \pm 0.1$ \\
\hline$\%$ of obesity & 63 & 55 & 50 & 32 \\
\hline \multirow{2}{*}{$\begin{array}{l}\text { WC, men } \\
\mathrm{cm}\end{array}$} & $106.9 \pm 2.1^{\prime \prime}$ & $103.7 \pm 2.8^{*}$ & $103.5 \pm 5.2$ & $96.3 \pm 0.48$ \\
\hline & $101.0 \pm 1.38^{\prime \prime}$ & $95.6 \pm 1.48^{\prime \prime}$ & $96.3 \pm 2.7^{\wedge}$ & $88.7 \pm 0.37$ \\
\hline & $106.7 \pm 1.7^{\wedge}$ & $105.9 \pm 2.8$ & $110.3 \pm 4.7$ & $101.2 \pm 0.3$ \\
\hline & $113.8 \pm 1.3^{\prime \prime}$ & $110.2 \pm 1.4^{\wedge}$ & $113.0 \pm 2.5^{\wedge}$ & $105.8 \pm 0.3$ \\
\hline \multirow{2}{*}{ WHR $\begin{array}{r}\text { men } \\
\text { women }\end{array}$} & $1.0 \pm 0.009^{\prime \prime}$ & $0.98 \pm 0.016$ & $0.94 \pm 0.016$ & $0.95 \pm 0.003$ \\
\hline & $0.89 \pm 0.007^{\prime \prime}$ & $0.87 \pm 0.007 "$ & $0.85 \pm 0.015$ & $0.84 \pm 0.002$ \\
\hline \multirow{2}{*}{$\begin{array}{l}\text { Average BP, } \\
\mathrm{mmHg}\end{array}$} & $135.2 \pm 2.0^{\prime \prime}$ & $125.6 \pm 1.7^{\prime \prime}$ & $129.6 \pm 3.4^{\wedge}$ & $119.7 \pm 0.4$ \\
\hline & $86.8 \pm 1.0^{\prime \prime}$ & $82.4 \pm 1.0^{\prime \prime}$ & $83.3 \pm 2.0 *$ & $78.3 \pm 0.3$ \\
\hline $\mathrm{AH}, \%$ & 60 & 50 & 47 & 28 \\
\hline CVD, $\%$ & $66 \%$ & 58 & 50 & 31 \\
\hline IVC, $\%$ & 12.2 & 14.3 & 42 & 15 \\
\hline $\begin{array}{l}\text { Low physical } \\
\text { activity, \% }\end{array}$ & 31 & 28 & 17 & 16 \\
\hline $\begin{array}{l}\text { History of } \\
\text { hyperglycemia, } \\
\%\end{array}$ & 28 & 5.4 & 11 & 2.2 \\
\hline $\begin{array}{l}\text { Average } \\
\text { FINDRISC score }\end{array}$ & $12.8 \pm 0.4 "$ & $11.4 \pm 0.4^{\prime \prime}$ & $11.0 \pm 0.8^{\prime \prime}$ & $8.0 \pm 0.09$ \\
\hline
\end{tabular}

IVC - Inadequate vegetables consumption; $*_{-} P<0.05,{ }^{\wedge}-P<0.01$, and "- $P<0.001$ - compared with individuals without $C M D$

J.Lindstrom and J.Tuomilehto ${ }^{(7)}$ wrote that $\mathrm{PhA}$ and consumption of fruits and vegetables did not have a big predictive value, but they were still included in the questionnaire to emphasize the importance of $\mathrm{PhA}$ and diet in diabetes prevention. In their study, DM was revealed in 3.5\% in 1987 and in $5.7 \%$ in 1992 (people who did not know about their disease before the study, and underwent a FINDRISC questionnaire scoring and OGTT). Interestingly, in the 1987 cohort, among 
people with a moderate risk of diabetes (score 4-8), diabetes developed in $2.4 \%$ within 10 years after the study, and only in $0.4 \%$ in the 1992 cohort. Perhaps this fact indicates the need for regular review and reassessment of the risk scale for the development of T2D, even in the same region.

The FINDRISC questionnaire was tested in adapted versions in 32 countries (at the time of publication of the seventh IDF Atlas in $2015^{(1)}$ ) with different efficiency. The difference in the effectiveness of the application of the questionnaire in different populations is determined not only by the characteristics of the surveyed population itself, but also by different values of the total score of the questionnaire, taken as a threshold for further examination-OTTG and/or HbAlc. Thus, in Botswana, ${ }^{(16)}$ the FINDRISC questionnaire showed moderate efficacy with a threshold value of 13 points: out of $14.4 \%$ of people with newly diagnosed diabetes, only $55 \%$ had a high and very high risk, according to the questionnaire. Authors from Nigeria ${ }^{(24)}$ and Colombia ${ }^{(25)}$ showed the effective use of the questionnaire with a threshold value of 14 points. In Spain ${ }^{(26)}$ and New Zealand, ${ }^{(18)}$ the threshold value was 12 points. In addition, Spanish authors have shown the effectiveness of a simplified version of the MADRISK questionnaire, which includes only BMI, a history of hyperglycemia, and antihypertensive therapy. In Greece, ${ }^{(27)}$ a second stage of screening has been proposed for individuals who score 15 points or more on the FINDRISC scale. In Germany, ${ }^{(28)}$ a simplified version has also been adopted, including age, BMI, and a history of hyperglycemia.

B. Omech et al. ${ }^{(16)}$ evaluated the applicability of the FINDRISC scale to the Botswana outpatient population. Sensitivity and specificity was $48 \%$ and $73 \%$, respectively. The authors concluded that the main limitation of the application of this questionnaire was the use of a non-standardized method for determining HbAlc in the country, as well as the lack of consideration given to cardiovascular risk factors and other conditions accompanied by insulin resistance, which need additional laboratory tests for diagnosis.

M.P. Silvestre et al. ${ }^{(18)}$ evaluated the applicability of the FINDRISC questionnaire to the New Zealand overweight population. The sensitivity of the questionnaire was 0.6026 and specificity - 0.5536. However, OTTG was performed only on individuals who scored more than 12 points on the questionnaire. The authors concluded that, in the New Zealand population, FINDRISC is an effective method for T2D and prediabetes screening for overweight residents.

A. Bernabe-Ortiz et al. ${ }^{(15)}$ attempted to develop and evaluate the use of a simple questionnaire, not including biochemical measurements, to screen for diabetes among the population of Peru. The predictors were age, diabetes in first-line relatives, and WC. The sensitivity of this evaluation method was $69 \%$ and specificity - $59 \%$.

In addition to the widespread FINDRISC questionnaire, questionnaires are being developed for individual countries, some of which include diabetes screening in the state program, and questionnaires are publicly available on government and health sites (for example, Canadian and Australian questionnaires for assessing the risk of T2D). ${ }^{(10,11)}$

In addition, the ADA has a test to determine the degree of risk for T2D, which is intended to be self-administered. ${ }^{(9,29)}$ It is understood that a person taking this test has information about the permissible weight and clearly represents the criteria for a sedentary lifestyle.

In a study among people of Uzbek nationality without impaired carbohydrate metabolism, $94.6 \%$ of the examined had a low, increased or moderate risk, according to the FINDRISC questionnaire (below 15 points). Among people with IFG, only $25 \%$ had a high risk of developing T2D (from 15 to 20 points), $21 \%$ - a moderate risk, $33 \%$ - an increased risk (from 7 to 11 points), and $21 \%$ - a low risk (lower 7 points). Among people with IGT, only $28.4 \%$ had a high risk of T2D, $25.9 \%$ - a moderate risk, $28.4 \%$ - an increased risk, and $17.3 \%$ - a low risk. Among people with diabetes diagnosed during the screening, only $33.9 \%$ had a high $(30 \%)$ and very high $(3.9 \%)$ risk of $\mathrm{T} 2 \mathrm{D}$, while $27.6 \%$ had a moderate risk, $30 \%$ - an increased risk, and 8.7\% - a low risk of T2D. Therefore, if, with the active screening for T2D among people of Uzbek nationality, we had only performed OGTT for people with a high and very high risk of T2D, according to the FINDRISC questionnaire, we would not have identified $66.3 \%$ of people with diabetes.

In our study among people of Uzbek nationality, in $61.4 \%$ of people with newly diagnosed diabetes and in $54.3 \%$ of people with IFG diagnosed by OGTT, the total score for the FINDRISC questionnaire was 12 or higher. At the same time, only $19.9 \%$ of people with normal OGTT results had a score above 12 (Table 4).

\section{Table 4.}

Percentage of people with and without CMD depending on the FINDRISC score in Uzbekistan

\begin{tabular}{|c|c|c|c|c|c|}
\hline FINDRISC score & $\begin{array}{c}\text { Without } \\
\text { CMD }\end{array}$ & IFG & IGT & IFG+IGT & $\begin{array}{c}\text { Newly } \\
\text { diagnosed } \\
\text { T2D }\end{array}$ \\
\hline$\geq 4$ & 80.8 & 91.7 & 93.8 & 100 & 97.6 \\
\hline$\geq 9$ & 44.2 & 70.8 & 72.8 & 75 & 86.6 \\
\hline$\geq 12$ & 19.9 & 45.8 & 54.3 & 62.5 & 61.4 \\
\hline
\end{tabular}

Thus, the sensitivity with a threshold value of 9 points was $87.9 \%$ and specificity was $45.3 \%$; with a value of 12 points, sensitivity was $71.6 \%$ and specificity was $54.8 \%$.

These results were the basis for a multivariate analysis of the risk for T2D among people of Uzbek nationality, and for the development of our own risk assessment program, taking into account new reference values of such anthropometric indicators as $\mathrm{WC}, \mathrm{HC}$ and $\mathrm{BMI} .{ }^{(20,21)}$

Thus, active screening is necessary for the early detection of T2D. The use of questionnaires to identify the risk for T2D has obvious advantages in order to increase the effectiveness of screening. However, the characteristics of the population (age, major risk factors) to be actively screened vary depending on nationality and place of residence. The use of the FINDRISC questionnaire in the Uzbek population 
is not effective enough to identify the maximum number of people in the high-risk group. In this regard, we recommend using our program for assessing the risk of T2D in the Uzbek population. ${ }^{(30)}$

\section{Acknowledgements}

Authors acknowledge their gratitude to Professor Zair S. Akbarov, Head of the Department of Diabetology at the RSSPMCE, and all endocrinologists who participated in the screening program.

\section{Sources of Funding}

Screening was performed within the state grant ADSS 15.12.2 "Improvement of prognosis, diagnosis and treatment of diabetes and its vascular complications based on screening, molecular-genetic studies and insulin pump therapy" (20152017).

\section{Disclosures}

None.

\section{References}

1. IDF Diabetes Atlas, Seventh Edition, 2015.

2. Beagley J, Guariguata L, Weil C, Motala AA. Global estimates of undiagnosed diabetes in adults. Diabetes Res Clin Pract. 2014 Feb;103(2):150-60. doi: 10.1016/j. diabres.2013.11.001.

3. IDF Clinical Practice Recommendations for Managing Type 2 Diabetes in Primary Care. International Diabetes Federation 2017.

4. Li R, Zhang P, Barker LE, Chowdhury FM, Zhang X. Cost-effectiveness of interventions to prevent and control diabetes mellitus: a systematic review. Diabetes Care. 2010 Aug;33(8):1872-94. doi: 10.2337/dc10-0843.

5. The WHO STEPwise approach to Surveillance of noncommunicable diseases (STEPS). World Health Organization 2003.

6. A call to Action on Diabetes. International Diabetes Federation, Belgium, November, 2010. Available at: https:// www.yumpu.com/en/document/read/6749334/call-to-actionon-diabetes-international-diabetes-federation

7. Lindstrom J, Tuomilehto J. The diabetes risk score: a practical tool to predict type 2 diabetes risk. Diabetes Care, 2003;26(3):725-31.

8. Saaristo T, Peltonen M, Lindstrom J, Saarikoski L, Sundvall J. Eriksson JG et al. Cross-sectional evaluation of the Finnish Diabetes Risk Score: a tool to identify undetected type 2 diabetes, abnormal glucose tolerance and metabolic syndrome. Diab Vasc Dis Res. 2005;2(2):67-72.

9. American Diabetes Association Standards of Medical Care in Diabetes - 2018. Diabetes Care. 2018;41(Supp 1):S2S159.

10. The Canadian Diabetes Risk Questionnaire CANRISK. Public Health Agency of Canada -2013.

11. The Australian Type 2 Diabetes Risk Assessment Tool (AUSDRISK). Australian Government. Department of Health and Aging. Canberra, 2010.
12. Wang A, Chen G, Su Zh, Liu X, Li H, Luo Ya, et al. Risk scores for predicting incidence of type 2 diabetes in the Chinese population: the Kailuan prospective study. Sci Rep. 2016 May 25;6:26548. doi: 10.1038/srep26548.

13. Heianza Y, Arase Y, Saito K, Hseih SD, Tsuji H, Kodama $\mathrm{S}$ et al. Development of a Screening Score for Undiagnosed Diabetes and Its Application in Estimating Absolute Risk of Future Type 2 Diabetes in Japan: Toranomon Hospital Health Management Center Study 10 (TOPICS 10). J Clin Endocrinol Metab. 2013 Mar;98(3):1051-60. doi: 10.1210/jc.2012-3092. 14. Nanri A, Nakagava T, Kuwahara K, Yamamoto S, Honda T, Okazaki H et al. Development of Risk Score for Predicting 3-Year Incidence of Type 2 Diabetes: Japan Epidemiology Collaboration on Occupational Health Study. PLoS One. 2015 Nov 11;10(11):e0142779. doi: 10.1371/journal.pone.0142779. 15. Bernabe-Ortiz A, Smeeth L, Gilman RH, Sanchez-Abanto JR, Checkley W, Miranda JJ, Study Group CC. Development and Validation of a Simple Risk Score for Undiagnosed Type 2 Diabetes in a Resource-Constrained Setting. J Diabetes Res. 2016;2016: 8790235.

16. Omech B, Mwita JC, Tshikuka JG, Tsima B, Nkomazna O, Amone-P'Olak K. Validity of the Finnish Diabetes Risk Score for Detecting Undiagnosed Type 2 Diabetes among General Medical Outpatients in Botswana. J Diabetes Res. 2016; 2016:4968350.

17. Robinson T, Elley CR, Wells S, Robinson E, Kenealy T, Pylypchuk R et al. New Zealand Diabetes Cohort Study cardiovascular risk score for people with type 2 diabetes: validation in the PREDICT cohort. J Prim Health Care. 2012;4(3):181-8.

18. Silvestre MP, Jiang Y, Volkova K, Chisholm H, Lee W, Poppitt SD. Evaluating FINDRISC as a screening tool for type 2 diabetes among overweight adults in the PREVIEW:NZ cohort. Prim Care Diabetes. 2017 Dec;11(6):561-569. doi: 10.1016/j.pcd.2017.07.003.

19. Recommendations on diabetes, prediabetes and cardiovascular diseases. EASD/ESC. Russian Journal of Cardiology. 2014;107(3):6-70. (in Russian)

20. Ismailov SI, Rakhimova GN, Alieva AV. Anthropometric reference data for Uzbek women. International Journal of Biomedicine. 2017;7(2):120-125.

21. Alieva AV, Ismailov SI, Rakhimova GN, Akbarov ZS. Anthropometric references for men of Uzbek nationality. NJDIS. 2017;(8):41-44.

22. WHO global strategy on diet, physical activity and health: European regional consultation meeting report. World Health Organization 2003. Available at: https://www.who.int/ dietphysicalactivity/media/en/gscon_cs_report_euro.pdf 23. Definition and diagnosis of diabetes mellitus and intermediate hyperglycemia. Report of a WHO/IDF consultation, 2006. Available at: https://www.who.int/ diabetes/publications/diagnosis_diabetes2006/en/

24. Olamoyegun AM, Oluyombo R, Iwuala OS. The Performance of the Finnish Diabetes Risk Score (FINDRISC) Questionaire for Screening Individuals with Undiagnosed Type 2 Diabetes and Dysglycaemia in Nigeria. Br British Journal of Medicine \& Medical Research. 2017;19(5):1-8. DOI: $10.9734 / \mathrm{BJMMR} / 2017 / 31022$

25. Gomez-Arbelaez D, Alvarado-Jurado L, Avala-Castillo M, Forero-Naranjo L, Camacho PA, Lopez-Jaramillo P. Evaluation of the Finnish Diabetes Risk Score to predict type 2 diabetes mellitus in a Colombian population: A longitudinal observational study. World J Diabetes. 2015 Dec 
10;6(17):1337-44. doi: 10.4239/wjd.v6.i17.1337.

26. Salinero-Fort MA, Burgos-Lunar C, Lahoz C, Mostaza JM, Abanades-Herranz JC, Laguna-Cuesta F et al. Performance of the Finnish Diabetes Risk Score and a Simplified Finnish Diabetes Risk Score in a Community-Based, Cross-Sectional Programme for Screening of Undiagnosed Type 2 Diabetes Mellitus and Dysglycaemia in Madrid, Spain: The SPREDIA-2 Study. PLoS One. 2016 Jul 21;11(7):e0158489. doi: 10.1371/ journal.pone.0158489.

27. Makrilakis K, Liatis S, Grammatikou S, Perrea D, Stathi C, Tsiligros P et al. Validation of the Finnish diabetes risk score (FINDRISC) questionnaire for screening for undiagnosed type 2 diabetes, dysglycaemia and the metabolic syndrome in Greece. Diabetes Metab. 2011 Apr;37(2):144-51. doi: 10.1016/j.diabet.2010.09.006.

28. Li J, Bergmann A, Reimann M, Bornstein SR, Schwarz PE. A more simplified Finnish diabetes risk score for opportunistic screening of undiagnosed type 2 diabetes in a German population with a family history of the metabolic syndrome. Horm Metab Res. 2009 Feb;41(2):98-103. doi: 10.1055/s-0028-1087191.

29. American Diabetes Association. Classification and Diagnosis of Diabetes. Diabetes Care. 2017;40 (Supp 1):S11S24.

30. Alieva AV, Rakhimova GN, Ismailov SI, Akbarov ZS. Assessment of risk for impaired glucose tolerance and type 2 diabetes mellitus in people of Uzbek nationality. Manual. Tashkent; 2017. [In Russian]. 